\title{
Melatonin Sensitivity to Dim White Light in Affective Disorders
}

\author{
Pradeep J. Nathan, Ph.D., Graham D. Burrows, M.D., and Trevor R. Norman, Ph.D.
}

Both dim and bright light has been shown to suppress the nocturnal secretion of the pineal hormone melatonin. Early reports suggests that an abnormal response to light occurs in patients with bipolar affective disorder, where as patients with major depressive disorder respond similarly to controls. It has been suggested that this abnormal sensitivity of the melatonin response to light could be a trait marker of bipolar affective disorder. However reports lack consistency. Hence, we investigated the melatonin suppression by dim light (200 lux) in patients with bipolar affective disorder, seasonal affective disorder and major depressive disorder. Results suggest that a supersensitive melatonin suppression to light in bipolar affective disorder $(\mathrm{p}<.005)$, and seasonal affective disorder $(\mathrm{p}<.05)$, whereas patients with major depressive disorder display similar suppression to controls. The supersensitivity may be a mechanism where by phase-delayed rhythms, are resynchronised to a new circadian position. Conversely, an abnormality may exist in the pathway from the retina to the suprachiamatic nucleus. [Neuropsychopharmacology 21:408-413, 1999] (C) 1999 American College of Neuropsychopharmacology. Published by Elsevier Science Inc.
KEY WORDS: Melatonin; Suppression; Dim-light; Affective disorders; Circadian rhythms; Biological marker; Lightsensitivity

In mammals, melatonin is a hormone secreted by the pineal gland in the hours of darkness. The regulation of melatonin synthesis and secretion, and synchronicity with the 24 hour clock, is achieved by the light-dark cycle which conveys information to the suprachiasmatic nucleus (SCN) via the retinohypothalamic tract (Lewy and Sack 1986). It is believed that light plays an important role by providing entrainment of circadian rhythms and by suppressing melatonin during the day (Cassone et al. 1993).

From the Brain Sciences Institute, Swinburne University of Technology, 400 Burwood Road, Hawthorn, 3122 Victoria, Australia (PJN); and the Department of Psychiatry, University of Melbourne, Austin \& Repatriation Medical Centre, Heidelberg, 3084 Victoria, Australia (GDB, TRN).

Address correspondence to: Pradeep J. Nathan, Ph.D., Brain Sciences Institute, Swinburne University of Technology, 400 Burwood Road, Hawthorn, 3122 Victoria, Australia. e-mail: pnathan@bsi. swin.edu.au

Received October 28, 1998; revised December 23, 1998; accepted January 07, 1999.
Interspecies and interindividual differences have been noted in pineal sensitivity to light (Laakso et al. 1991), and initial reports suggested humans were insensitive to light at night (Vaughan et al. 1979). Further studies have contradicted these results, suggesting only quantitative differences between species, with very bright light (above 1500 lux) sufficient to suppress human nocturnal melatonin secretion (Lewy et al. 1980). More recent studies have investigated the relationship between light intensity and melatonin suppression. Whilst some researchers have reported no differences in melatonin response to varying light intensities (1000 lux and 2500 lux) (Boyce and Kennaway 1987), more recent reports have suggested that humans are sensitive to lower levels of light (300 lux) (Bojkowski et al. 1987). McIntyre et al. (1989a) also reported a response to low levels of light and suggested an intensity dependent relationship between light and percentage of nocturnal melatonin suppression (3000, 1000, 500, 350, and 200 lux), with no gender differences (Nathan et al. unpublished observations).

Reports of disturbed circadian rhythms in patients with bipolar disorder (periodic episodes of mania and 
depression) and seasonal patterns of high incidence of the disorder (Duncan 1996) have encouraged the speculation that photoperiodic mechanisms (such as the light dark cycle) interacting with the circadian system might be involved in the aetiology of bipolar disorder (Kripke et al. 1978; Duncan 1996). Whilest initial reports suggested little or no effect of dim light on melatonin secretion in humans, the effect of light on the suppression of melatonin in patients with bipolar disorder has been investigated. Early reports suggested bipolar disorder patients were supersensitive to the effects 500 lux of light (Lewy et al. 1981) and that this may be a trait marker for the illness (Lewy et al. 1985). Nurnberger et al. (1988) have taken this hypothesis further and investigated familial sensitivity as a possible genetic marker. It was reported that the supersensitivity in the melatonin response to light was more likely amongst those with a parent with bipolar disorder. Others have reported no increased sensitivity to light in patients with bipolar disorder or patients with major depressive disorder compared to controls, but that those diagnosed as bipolar disorder had significantly lower baseline melatonin levels (Cummings et al. 1989; Lam et al. 1990). Whalley et al. (1990) also reported no differences in sensitivity to 500 lux between euthymic (recovered) bipolar patients and control subjects. These results are therefore in conflict with those reported findings of Lewy et al. (1985).

Patients with seasonal affective disorder (SAD) may also show a supersensitive response to dim or bright light compared to controls (Thompson et al. 1990; McIntyre et al. 1990). Supersensitivity was only found in the winter months suggesting an abnormal seasonal and state dependent variation in the suppression of melatonin by light in SAD. However, Murphy et al. (1990) found no abnormalities in a group of patients with SAD when exposed to bright light.

We investigated the nocturnal melatonin response to 200 lux of light in a group of controls and patients with bipolar disorder, seasonal affective disorder and major depressive disorder.

\section{METHODS}

Patients attending for psychiatric treatment at the North Eastern Health Care Network Psychiatric services in Melbourne, Australia were selected for the study. Patients selected were without any cormorbid conditions and in good physical health, and met the DSM-IV (American Psychiatric Association 1994), criteria for the diagnosis of bipolar disorder (BD), seasonal affective disorder (SAD) and major depressive disorder (MDD). Patients selected also met the DSM-IV criteria for moderate to severe illness as assessed by a qualified psychiatrist (Hamilton Depression Score > 20). All pa- tients with MDD and SAD were drug free for at least two weeks prior to the study. All patients with BD except two (two out of eight patients) were on medication. These patients were on either lithium, lithium and benzodiazepine combination or Lithium and a serotonin re-uptake inhibitor (SSRI) combination. None of the controls had any personal or family history of major affective disorder, bipolar disorder, or any anxiety disorders, and were free of any medication and serious physical illness. All subjects gave written informed consent to participate in the study, which was approved by the Committee of Human Ethics in Research, of the Austin and Repatriation Medical Centre.

The study was conducted over a two year period, on single nights throughout all seasons. Patients with SAD were only tested in winter. Sixty three controls (aged 18-56 years; mean \pm SEM, $26.6 \pm 0.1$ years), eight bipolar patients (aged 23-72 years; mean \pm SEM, $44.9 \pm 5.2$ years), six seasonal affective disorder patients (aged 2759 years; mean \pm SEM, $46.3 \pm 5.3$ years) and nine major depressive disorder patients (aged 23-48; mean \pm SEM, $35 \pm 2.6$ years) completed the study. Both controls and patients were required to attend the University of Melbourne, Department of Psychiatry at $2000 \mathrm{hr}$ on one night. A butterfly catheter (21 gauge) was inserted into each subjects median vein of the forearm (within the cubital fossa). The catheter was kept patent with heparinised saline (50 IU per $5.0 \mathrm{ml}$ ). The first blood sample was collected at $2100 \mathrm{hr}$ (in the light) into heparinised plastic tubes. Controls or patients were then placed in a dark room, with a background light intensity of 10-20 lux (20 times less intense than the intensity required to suppress melatonin by 16\% (McIntyre et al. 1989a). Further blood samples were collected at the following times; $2200 \mathrm{hr}, 2300 \mathrm{hr}, 2330 \mathrm{hr}, 2345 \mathrm{hr}, 2400 \mathrm{hr}, 0030$ hr, 0045 hr, 0100 hr, 0130 hr, 0200 hr and 0230 hr. Controls or patients on each night were exposed to 200 lux of light between $2400 \mathrm{hr}$ and $0100 \mathrm{hr}$, using two Triphoshor high grade $\left(500^{\circ} \mathrm{K}\right)$ fluorescent tubes. Light exposure was between $2400 \mathrm{hr}$ and $0100 \mathrm{hr}$ in a sitting position.

Blood samples were immediately centrifuged for 15 min at $1000 \mathrm{~g}$ after collection, plasma was aliquoted and frozen at $-20^{\circ} \mathrm{C}$. Plasma melatonin was measured by a specific radioimmunoassay by the method of Fraser et al. (1983). The limit of detection of the assay was $1 \mathrm{pg} / \mathrm{ml}$ and the interassay coefficients of variation were less than $12 \%$ for a plasma pool in the range of 15 to $65 \mathrm{pg} / \mathrm{ml}$.

The percent suppression of melatonin was calculated for each subject on the night of light exposure using the formula; $[(a-b) / a] \times 100$, where $a=$ the average melatonin level at $2345 \mathrm{hr}$ and $2400 \mathrm{hr}$ and b = the average melatonin level at $0045 \mathrm{hr}$ and $0100 \mathrm{hr}$ as described in McIntyre et al. (1989a). A repeated measures analysis of variance (ANOVA) was conducted to examine the within subjects effect of time and the between subjects effect of psychiatric diagnosis. The percentage suppres- 
sion of melatonin between groups was analysed using a one-way ANOVA. Differences between groups were investigated using the Student Newman's Keuls (SNK) post hoc test. All tests were carried out using the statistical program SPSS (SPSS 1986).

\section{RESULTS}

The mean nocturnal melatonin concentration vs time in patients with bipolar disorder, major depressive disorder and seasonal affective disorder are shown on Fig- (a)

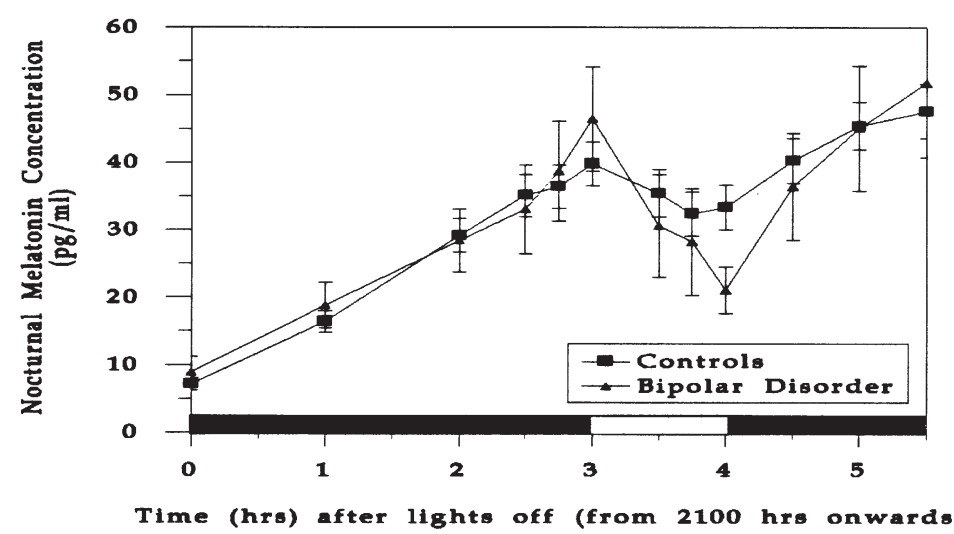

(b)

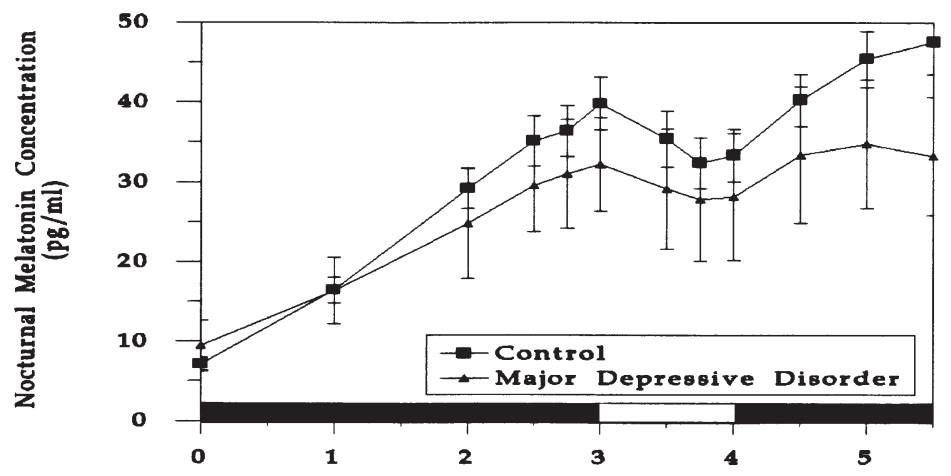

(c)

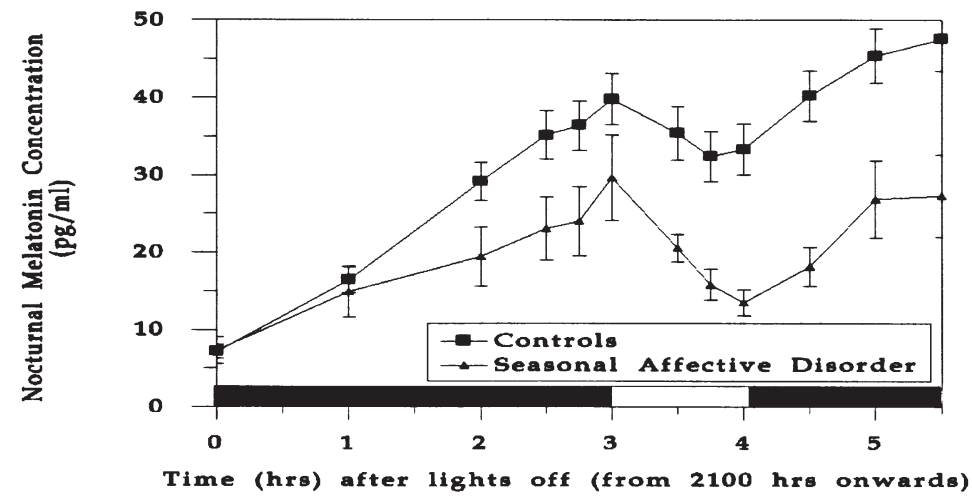

Figure 1. Nocturnal melatonin profile for patients with bipolar disorder (a), major depressive disorder (b), and seasonal affective disorder (c) compared to controls. Results are expressed as mean \pm SEM. 


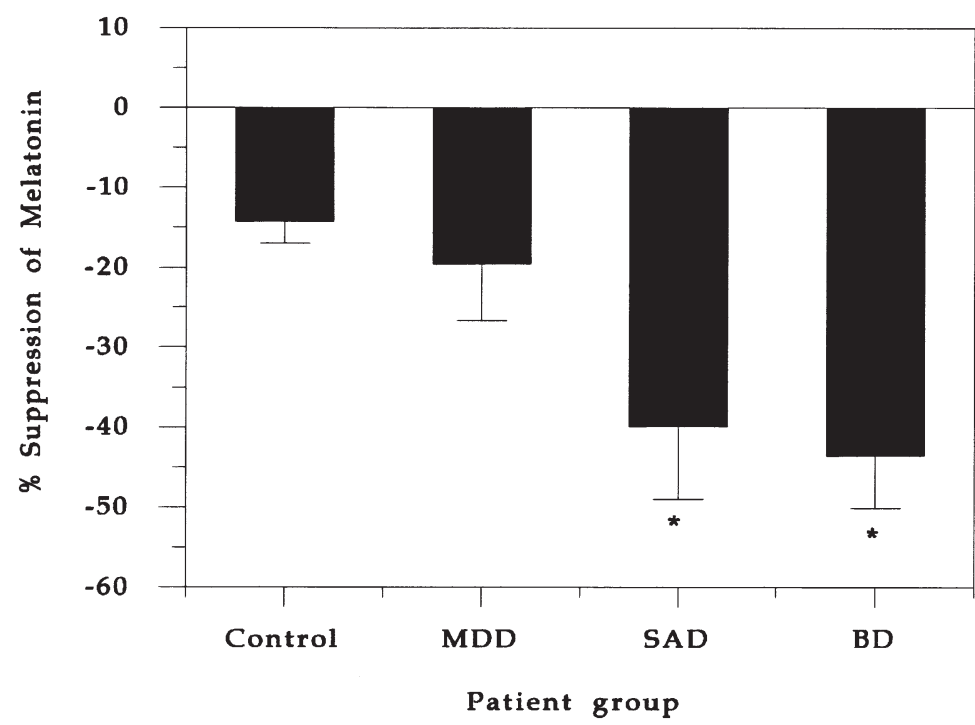

Figure 2. Percentage suppression of melatonin in patient groups compared to controls. MDD, major depressive disorder; SAD, seasonal affective disorder; $\mathrm{BD}$, bipolar disorder. ${ }^{*} p<.05$, compared to control and MDD. Results are expressed as mean \pm SEM.

ures $1 \mathrm{a}, \mathrm{b}$, and c, respectively. Repeated measures analysis of variance (ANOVA) showed a significant effect of time $\left(\mathrm{F}_{11,33}=22.2, p<.0005\right)$. No statistically significant differences were found with diagnosis $\left(\mathrm{F}_{3,80}=1.06, p=\right.$ $.37)$, or time by diagnosis $\left(\mathrm{F}_{33,880}=1.27, p=.14\right)$. The mean percentage suppression of melatonin by 200 lux of light in the patient groups compared to control is shown on Figure 2. A one-way ANOVA conducted on the percentage suppression of melatonin showed significant differences between diagnostic groups $\left(\mathrm{F}_{3,82}=\right.$ 6.73, $p<$.0005; Figure 2). Individual comparisons between groups were analysed using the SNK post hoc test and significant differences were found between some groups. (F-values indicated in Table 1).

\section{DISCUSSION}

The first finding of the present study is that patients with BD are supersensitive with respect to their melatonin suppression by dim light compared to controls. In contrast patients with MDD did not demonstrate significantly different suppression of nocturnal plasma melatonin concentrations following light exposure when compared to controls. The findings are similar to that of

Table 1. Summary of Statistical Results Showing Significant Differences between Diagnostic Groups

\begin{tabular}{lrcccc}
\hline & & \% Suppression & SAD & MDD & Controls \\
\hline BD & 8 & -43.57 & 3.66 & $24.0^{a}$ & $29.24^{a}$ \\
SAD & 6 & -39.91 & & $20.34^{a}$ & $25.28^{a}$ \\
MDD & 9 & -19.57 & & & 5.24 \\
Controls & 63 & -14.33 & & & \\
\hline
\end{tabular}

${ }^{a} p<0.05$.
Lewy et al. (1981, 1985) and Nurnberger et al. (1988) who likewise found a supersensitivity in bipolar patients, and Cummings et al. (1989) who found no difference in the light sensitivity between controls and patients with MDD. However, the study does not agree with a more recent study that showed more suppression in the controls than in a group of patients with MDD or BD (Lam et al. 1990), and the study of Whalley et al. (1990) showing no differences in sensitivity to 500 lux between euthymic (recovered) bipolar patients and control subjects.

The second finding form the present study is that patients with SAD also showed a supersensitive melatonin suppression to dim light. A supersensitivity in SAD patients has been noted previously (Thompson et al. 1990; McIntyre et al. 1990). According to one hypothesis, winter depressives are supersensitive to light and become ill in the winter because centers in the brain that monitor seasonal changes in day length respond inappropriately to artificial light (Wehr 1992). This supersensitivity has been shown to be state dependent, and revert to normal during summer or treatment with light (Wehr 1992). However a study by Murphy et al. (1990) found no difference in the sensitivity of melatonin to bright light between controls and SAD patients. It was suggested that the lack of significance seen in the latter study was due to a lack of a dim light control night, and the fact that the test was not repeated in summer (Thompson et al. 1990). This may not be a factor as the present study found significant differences between the groups, and no control dim light test night was conducted, nor was the test repeated in summer.

The similar suppression of melatonin found in patients with SAD and BD is not surprising given that the original definition of SAD was made from an observation of Rosenthal (1984), in a bipolar patient who developed seasonal recurrent winter depressions. More re- 
cently a study suggested that the relapse of BD was associated with seasonal factors (Silverstone et al. 1995).

An important aspect of differences between studies may be attributed to varying methodologies between studies. It has been suggested that inconsistent findings may be attributed to factors that affect the melatonin response to light. However, our preliminary studies have examined some factors that affect the melatonin suppression by light and we have shown that factors such as age, gender, season, and menstrual cycle variations do not affect the light sensitivity to 200 lux (Nathan et al. unpublished observations). Hence the differences observed at least in the present study with 200 lux, may be due to an underlying abnormality in patients with $\mathrm{BD}$ and SAD.

The precise mechanism involved in the apparent supersensitivity of the melatonin response to light in $\mathrm{BD}$ and SAD is not known. The most likely site of the abnormal sensitivity may be the suprachiamatic nucleus, and/or specific neurotransmitter or receptor systems in the retinohypothalamic tract. Lewy et al. (1985) suggested that the supersensitivity seen in patients with BD could explain the observations of phase-advanced circadian rhythms in patients with affective disorders. It was hypothesised that increasing zeitgeber sensitivity (time cue/light) would advance the circadian position, a consistent finding in some patients with affective disorders (Lewy et al. 1983; Wehr and Goodwin 1981). Similarly, the circadian rhythms of patients with SAD become phase-delayed in winter (Lewy et al. 1983), and a greater sensitivity to the zeitgeber may be associated with a more advanced circadian position (Minors and Waterhouse 1981). In both disorders the supersensitivity may be a mechanism whereby the circadian rhythms re-adjust with respect to the environmental day.

Alternatively, the mechanism involved in the supersensitivity may be a dysfunctional neurotransmitter/ receptor system. The neuronal pathway from the retina to the SCN (via the retinohypothalamic tract) mediates the suppressive effect of light and the entrainment of the melatonin rhythm to the light/dark cycle (Moore and Lenn 1972). Previous studies have indicated that excitatory amino acids may be involved in photic entrainment of circadian rhythms and melatonin production (Cowell et al. 1991; Ohi et al. 1993; Poeggeler et al. 1995). Further studies have shown that glutamate, the dominant excitatory neurotransmitter in the central nervous system, mediates photic entrainment (DeVries et al. 1993). Pharmacological studies have revealed that antagonists of postsynaptic receptors that mediate the actions of this neurotransmitter block the light induced suppression of melatonin (Cowell et al. 1991; Ohi et al. 1993). Hypothalamic $N$-methyl- $D$-aspartate (NMDA) receptors coupled to a nitric oxide/cGMP signaling pathway have been identified (Amir 1992; Cowell et al. 1990; Mikkelsen et al. 1995; Poeggeler et al. 1995). The observed supersensitivity to light in patients with $\mathrm{BD}$ and SAD may thus be related to a NMDA receptor mediated mechanism.

Our present finding suggests that melatonin supersensitivity to light may be a trait marker specific for BD. However, the supersensitivity observed in SAD may be a state marker of the disorder as supersensitivity only persists in winter months (Thompson et al. 1990). More studies are warranted to determine if the supersensitivity to light is a trait marker of BD. Furthermore studies in SAD patients in both summer and winter is required to determine if the supersensitivity is a state marker of SAD.

\section{ACKNOWLEDGMENT}

Authors wish to thank the Theodore \& Vada Stanley Foundation for their financial support, and Angela Komiti and Jacqueline McGrath for their assistance during the study.

\section{REFERENCES}

American Psychiatric Association (1994): Diagnostic and Statistical Manual of Mental Disorders, 4th ed. Washington, D.C, APA

Amir S (1992): Blocking NMDA receptors or nitric oxide production disrupts light transmission to the suprachiasmatic nucleus. Brain Res 586:336-339

Bojkowski CJ, Aldhous ME, English J, Franey C, Poulton AL, Skene DJ, Arendt J (1987): Suppression of nocturnal plasma melatonin and 6-sulphatoxymelatonin by bright light and dim light in man. Horm Metabol Res 19:437440

Boyce P, Kennaway DJ (1987): Effects of light on melatonin production. Biol Psychiatry 22:473-478

Cassone VM, Warren WS, Brooks, DS, Lu J (1993): Melatonin the pineal gland and circadian rhythms. J Biol Rhythms 8(suppl):S73-S81

Cowell CS, Ralph MR, Menaker M (1990): Do NMDA receptors mediate the effects of light on circadian behaviour. Brain Res 523:117-120

Cowell CS, Foster RG, Menaker M (1991): NMDA receptor antagonists block the effects of light on circadian behaviour in the mouse. Brain Res 554:105-110

Cummings MA, Berga SL, Cummings KL, Kripte DF, Haviland MG, Golshan S, Gillin JC (1989): Light suppression of melatonin in unipolar depressed patients. Psychiatry Res 27:351-355

DeVries MJ, Cardozo BN, Vander Want J, DeWolf A, Meijer JH (1993): Glutamate immunoreactivity in terminals of the retinohypothalamic tract of the Norwegian rat. Brain Res 506:231-234

Duncan WC (1996): Circadian rhythms and the pharmacology of affective illness. Pharmacol Ther 71(3):253-312

Fraser S, Cowen P, Franklin M, Franey C, Arendt J (1983): A direct radioimmunoassay for melatonin. Clin Chem 29:396-399 
Kripke DIF, Mullaney DJ, Atkinson M, Wolf S (1978): Circadian rhythm disorders in manic depressives. Biol Psychiatry 13:335-351

Laakso, ML, Porkka-Heiskanen T, Stenberg D, Alila A (1991): Interindividual differences in the reponses of serum and salivary melatonin to light. In Fraschini F, Reiter RJ (eds), Role of Melatonin and Pineal Peptides in Neuroimmunomodulation. New York, Plenum Press, pp 1-60

Lam RW, Berkowitz AL, Berga SL, Clark CM, Krepke DF, Gillin JC (1990): Melatonin suppression in bipolar and unipolar mood disorders. Psychiatry Res 32:129-134

Lewy AJ, Wehr TA, Goodwin FK, Newsome DA, Markey SP (1980): Light suppress melatonin secretion in humans. Science 210:1267-1269

Lewy AJ, Wehr TA, Goodwin FK, Newsome DA, Rosenthal NE (1981): Manic-depressive patients may be supersensitive to light. Lancet 1:383-384

Lewy AJ, Brainard G, Menaker M (1983): Fluence-response relationship between light radiance suppression of melatonin reduction and treatment of winter depression (letter). Neuroendocrinol Lett 5:409

Lewy AJ, Nurnberger JI, Wehr TA, Pack D, Becker LE, Powell RL, Newsome DA (1985): Supersensitivity to light: possible trait marker for manic-depressive illness. Am J Psychiatry 142(6):725-727

Lewy AJ, Sack RL (1986): Biological Rhythms and behaviour in humans: the effect of light. In Dennerstein L, Fraser I (eds), Hormones and behaviour. New York, Elsevier, B.V

McIntyre IM, Norman TR, Burrows GD, Armstrong SM (1989a): Human melatonin suppression by light is intensity dependent. J Pineal Res 6:149-156

McIntyre IM, Norman TR, Burrows GD, Armstrong SM (1990): Melatonin supersensitivity to dim light in seasonal affective disorder. Lancet 335:488

Minors DS, Waterhouse JM (1981): Circadian rhythm in patients with SAD. In Wright J (ed), Circadian Rhythms and the Human. London, Elsevier, pp 3-20

Mikkelsen JD, Larsen PJ, Mick G, Vrang N, Ebling FJP, Maywood ES, Hastings MH, Moller M (1995): Gating of retinal imputs through the suprachiasmatic nucleus: role of excitatory neurotransmission. Neurochem Int 27(3): 263-272

Moore RY, Lenn NJ (1972): A retinohypothalamic projection in the rat. J Comp Neurol 146:1-14
Murphy DGM, Abas M, Winton F (1990): A neurophysiological approach. In Thompson C, Silverstone T (eds), Seasonal Affective Disorders. London, Farrand Press, pp 233-242

Nurnberger JI, Berrettini WH, Tamrkin L, Hamovit J (1988): Supersensitivity to light in youg people at high risk for affective disorder: a priliminary report. Neuropsychopharmacology 1(3):217-223

Ohi K, Takashima M, Nishihawa T, Takahashi K (1993): $\mathrm{N}$-methyl-D-aspartate receptor participates in neural transmission of photic information through the hypothalamic tract. Neuroendocrinology 53:344-348

Poeggeler BH, Barlow-Walden LR, Reiter RJ, Sarela S, Pelaez AM, Yaga K, Manchester LC, Chen LD (1995): Red light induced suppression of melatonin synthesis is mediated by N-methyl-D-aspartate receptor activation in retinally normal and retinally degererate rats. J Neurobiol 28(1):1-8

Rosenthal NE, Sack DA, Gillin JC, Lewy AJ, Goodwin FK, Davenport Y, Mueller PS, Newsome DA, Wehr TA (1984): Seasonal affective disorder. A description of the syndrome and preliminary findings with light therapy. Arch Gen Psychiatry 41:72-80

Silverstone T, Romans S, Hunt N, McPherson H (1994): Is there a seasonal pattern of relapse in bipolar affective disorder? A dual northern and southern heisphere study. Br J Psychiatry 167:58-60

SPSS (1986): SPSS ${ }^{x}$ Users Manual. Mahwah, New Jersey, McGraw-Hill Book Company \& SPSS Inc, pp 863

Thompson C, Stinson D, Smith A (1990): Seasonal affective disorder and season-dependent abnormalities of melatonin suppression by light. Lancet 336:703-706

Vaughan GM, Bell R, De La Pena (1979): Nocturnal plama melatonin in humans: episodic pattern and influence of light. Neurosci Lett 14:81-84

Whalley LJ, Perini T, Shering A, Bennie J (1990): Melatonin response to bright light in recovered, drug free, bipolar patients. Pscyhiatry Res 38:13-19

Wehr TA, Goodwin FK (1981): Biological rhythms and psychiatry. In Arieti S (ed), American Handbook of Psychiatry, 2nd ed., vol 7. New York, Basic Books, pp 320-340

Wehr TA (1992): Seasonal vulnerability to depression: Implications for etiology and treatment. L'Encephale XVIII:479483 